\title{
Effects of reduced $\beta 2$ glycoprotein I on high glucose-induced cell death in HUVECs
}

\author{
JING-YUN ZHANG，JUN MA，PEI YU，GUANG-JIE TANG，CHUN-JUN LI，DE-MIN YU and QIU-MEI ZHANG \\ Key Laboratory of Hormones and Development (Ministry of Health), \\ Tianjin Key Laboratory of Metabolic Diseases, Tianjin Metabolic Diseases Hospital and \\ Tianjin Institute of Endocrinology, Tianjin Medical University, Tianjin 300070, P.R. China
}

Received September 20, 2016; Accepted May 25, 2017

DOI: $10.3892 / \mathrm{mmr} .2017 .7065$

\begin{abstract}
Reduced $\beta 2$ glycoprotein I ( $\beta 2 \mathrm{GPI})$ has been demonstrated to exhibit a beneficial effect in diabetic atherosclerosis and retinal neovascularization. However, the effect of reduced $\beta 2 \mathrm{GPI}$ on vascular disorders in diabetic mellitus (DM) remains to be elucidated. The present study established a high glucose-induced injury model using human umbilical cords veins (HUVECs) and evaluated the protective effects of reduced $\beta 2 \mathrm{GPI}$ against the injury. The data demonstrated that a low concentration of reduced $\beta 2 \mathrm{GPI}(0.5 \mu \mathrm{M})$ mitigated high glucose-induced cell loss, decreased nitric oxide (NO) production and resulted in calcium overloading. Mechanically, reduced $\beta 2$ GPI additionally reversed high glucose-induced phosphatase and tensin homolog (PTEN) accumulation, decrease of protein kinase B phosphorylation and nitric oxide synthase activity, and increase of cyclooxygenase-2 activity. It was further confirmed that PTEN inhibitor-bpV $(1 \mu \mathrm{M})$ exhibited similar effects to those resulting from reduced $\beta 2 \mathrm{GPI}$. Overall, the data revealed that reduced $\beta 2$ GPI exerts protective effects from glucose-induced injury in HUVECs, potentially via decreasing PTEN levels. The present study suggests reduced $\beta 2$ GPI may act as a novel therapeutic strategy for the treatment of vascular disorders in DM.
\end{abstract}

\section{Introduction}

Atherosclerosis is one of the severe microvascular complications of diabetes mellitus (DM). Epidemiological studies demonstrate that hyperglycemia is the most consistent symptom that reveals a significant association with the development

Correspondence to: Dr Qiu-Mei Zhang, Key Laboratory of Hormones and Development (Ministry of Health), Tianjin Key Laboratory of Metabolic Diseases, Tianjin Metabolic Diseases Hospital and Tianjin Institute of Endocrinology, Tianjin Medical University, 66 Tongan Road, Tianjin 300070, P.R. China E-mail: qiumei_zhang1@sina.com

Key words: reduced $\beta 2$ glycoprotein I, human umbilical cord veins, phosphatase and tensin homolog, nitric oxide of vascular disorders in DM (1). However, the mechanisms for the vascular disorders in DM remain to be elucidated. Endothelial cell dysfunction has been demonstrated to occur in diabetes (2-4), and functional recovery of these cells may aid in therapeutically resolving the vascular complications that occur in DM.

$\beta 2$ glycoprotein I ( $\beta 2 \mathrm{GPI})$ has been identified as the most prominent antigen in antiphospholipid syndrome $(5,6)$. $\beta 2 \mathrm{GPI}$ is predominantly synthesized in hepatocytes (7) and consists of five repeating amino acid domains. Domains I-IV include four cysteines each and have the conserved sequences, whereas domain $\mathrm{V}$ has an extra 20 amino acid tail with a unique cysteine termination (8). It has previously been demonstrated that the disulfide bond between Cys288 to Cys326 in domain V may be reduced by thioredoxin-1 (TRX-1) or protein disulfide isomerase (PDI) (9), resulting in the reduced state of $\beta 2 \mathrm{GPI}$, referred to as reduced $\beta 2 \mathrm{GPI}$.

Although $\beta 2$ GPI has been revealed to participate in the autoimmune system, vascular thrombosis, infectious diseases and other systems (10-12), the specific function of $\beta 2 \mathrm{GPI}$ in $\mathrm{DM}$ remains to be elucidated. It has been reported that $\beta 2 \mathrm{GPI}$ is associated with accelerated atherosclerosis and enhanced oxidative stress (13), whereas reduced $\beta 2$ GPI protects endothelial cells from oxidative stress-induced injury (13). The authors previously demonstrated that reduced $\beta 2 \mathrm{GPI}$ is beneficial in diabetic atherosclerosis and retinal neovascularization (14). However, no studies have examined the association between reduced $\beta 2 \mathrm{GPI}$ and microvascular disorders in DM. The present study hypothesizes that reduced $\beta 2 \mathrm{GPI}$ exhibits beneficial effects in microvascular disorders in DM.

\section{Materials and methods}

Cell culture. Briefly, human umbilical cord tissues were harvested from 12 women who had normal delivery (age range 25-35 years, average, 31.4 years) at Tianjin Medical University Metabolic Diseases Hospital (Tianjin, China). Endothelial cells from human umbilical cords veins (HUVECs) were harvested as previously described (15). Written consent was obtained from each patient. All protocols were approved by the Ethical Committee of Tianjin Medical University Metabolic Disease Hospital (Tianjin, China), ethics protocol number: DXBYYhMEC2017-11. Briefly, human umbilical cord tissues 
were digested by $0.05 \%$ collagenase for $15 \mathrm{~min}$ at $37^{\circ} \mathrm{C}$. The cells were collected and grown in M199 medium (Gibco; Thermo Fisher Scientific, Inc., Waltham, MA, USA) supplemented with $20 \%$ fetal calf serum (Hyclone; GE Healthcare Life Sciences, Logan, UT, USA) at $37^{\circ} \mathrm{C}$ in a humidified atmosphere containing $5 \% \mathrm{CO}_{2}$. Adherent cells were harvested following trypsin-EDTA treatment $(0.05 \%)$. Culture medium was replaced every 2 days and adherent cells were identified by their cobblestone appearance at confluence and positive labelling with mouse FITC-conjugated antihuman factor VIII (1:1,000, ab41187; Abcam, Cambridge, UK) detected by flow cytometry as previously described (15).

Purification of $\beta 2$ GPI and preparation of reduced $\beta 2 G P I$. $\beta 2 \mathrm{GPI}$ was purified from normal human plasma extracted from a total of 10 male volunteers (age range 20-40 years, average 35 years) (Tianjin Medical University Metabolic Disease Hospital) as previously described (16). Venous blood $(50 \mathrm{ml})$ was collected and plasma was obtained following centrifugation at $4^{\circ} \mathrm{C}, 987 \mathrm{x}$ g for $10 \mathrm{~min}$. Written informed consent was obtained from each volunteer. Reduced $\beta 2 \mathrm{GPI}$ was prepared as previously described (17). In brief, purified $\beta 2 \mathrm{GPI}(2 \mu \mathrm{M})$ was reduced by TRX-1 $(3.5 \mu \mathrm{M})$ activated with dithiothreitol (DTT, $70 \mu \mathrm{M}$ ). The thiols of reduced $\beta 2 \mathrm{GPI}$ were protected by reduced glutathione. The reduced $\beta 2$ GPI was verified using western blotting and liquid chromatography-mass spectrometry analysis as previously described (14).

Cell viability. HUVECs were seeded in a 96-well culture plate and cultured for 5 days at $37^{\circ} \mathrm{C}$ in a humidified atmosphere containing $5 \% \mathrm{CO}_{2}$. Different concentrations of reduced $\beta 2 \mathrm{GPI}(0.25-1 \mu \mathrm{M})$ were incubated with the cells. A total of 24, 48 and $72 \mathrm{~h}$ following incubation, the cell viability was detected by an MTT assay. The effect of reduced $\beta 2 \mathrm{GPI}$ was compared with the non-reduced $\beta 2 \mathrm{GPI}$. High glucose (44.4 $\mathrm{mM}$ ) was applied to model cell injury and the protective effects of reduced $\beta 2$ GPI on cell death compared to vehicle (TRX-1, DTT and glutathione) were analyzed. Following application of the aforementioned treatments, $20 \mu 1 \mathrm{MTT}$ $(5 \mathrm{mg} / \mathrm{ml})$ was added into the $180 \mu \mathrm{l}$ culture medium in each well. The medium was removed following $4 \mathrm{~h}$, and $150 \mu \mathrm{l}$ dimethyl sulfoxide was added into each well to dissolve the precipitation. The absorbance was measured at a wavelength of $490 \mathrm{~nm}$ using an automated microplate reader (Multiskan FC; Thermo Fisher Scientific, Inc., Waltham, MA, USA). Cell viability was calculated using the following formula: Cell viability $(\%)=$ average absorbance of treated group/average absorbance of control group x $100 \%$.

Detection of intracellular free $\mathrm{Ca}^{2+}$. Intracellular free $\mathrm{Ca}^{2+}$ levels were detected by a fluo 3/-acetoxymethyl (AM) kit (Beyotime Institute of Biotechnology, Ningbo, China) following the manufacturer's protocol. HUVECs were seeded in a 96-well culture plate and cultured for 5 days. Following various treatments for $48 \mathrm{~h}$, the cells were washed with PBS and incubated in serum-free medium containing $5 \mu \mathrm{M}$ flura-3/AM for $60 \mathrm{~min}$ at $37^{\circ} \mathrm{C}$. Following this, the cells were washed with PBS and cultured for a further $25 \mathrm{~min}$ to ensure fluro-3/AM conversion into fluro-3 in cells. The excitation and emission wavelengths were set at 488 and
$530 \mathrm{~nm}$ respectively to measure fluro-3 fluorescence using a microplate reader.

Determination of total nitric oxide (NO), NO synthase (NOS) and cyclooxygenase (COX)-2 activity. HUVECs were seeded in a 12-well culture plate and cultured for 5 days. Following various treatments, the culture medium was collected to measure the NO level using a NO assay kit (A012; Nanjing Jiancheng Bioengineering Institute, Nanjing, China). The absorbance was detected by a spectrophotometer set at a wavelength of $540 \mathrm{~nm}$. Nitric oxide synthase (NOS) activity was detected following the kit manufacturer's protocol (S0025; Beyotime Institute of Biotechnology). Following various treatments, the cells were collected to measure the NOS activity. COX-2 activity was detected following the kit manufacturer's protocol (ab210574; Abcam). Following various treatments, the cells were collected to measure the COX-2 activity. The levels of NO, NOS and COX-2 were calculated as follows: [(Absorbance of treated wells-absorbance of blank wells)/(absorbance of standard wells-absorbance of blank wells)] x standard concentration $(100 \mu \mathrm{M})$.

Immunoblot analysis. Cytoplasmic protein was isolated using the Cytoplasmic Protein Extraction kit (Beyotime Institute of Biotechnology) according to the manufacturer's protocol. The cells were treated with high glucose and/or $\beta 2$ GPI and washed with $1 \mathrm{ml}$ ice-cold PBS, and collected and centrifuged for $5 \mathrm{~min}$ at $1,158 \mathrm{x} \mathrm{g}$ at $4^{\circ} \mathrm{C}$. Protein concentration was detected using the BCA method (Beyotime Institute of Biotechnology), and an equal amount of protein $(20 \mu \mathrm{g})$ was loaded onto $10 \%$ sodium dodecyl sulfate-polyacrylamide gel electrophoresis gels. The nitrocellulose membranes were blocked with $5 \%$ non-fat milk for $2 \mathrm{~h}$ at room temperature and subsequently incubated with anti-phosphatase and tensin homolog (PTEN, 1:1,000; no. 9552), anti-protein kinase B (AKT, 1:1,000; no. 9272), anti-phospho (p)-AKT $(1: 1,000 ;$ no. 12694$)$ and anti-actin $(1: 5,000 ;$ no. 12262) (all from Cell Signaling Technology, Inc., Danvers, MA, USA) primary antibodies at $4^{\circ} \mathrm{C}$ overnight. Following washing, the membranes were incubated with a secondary antibody (1:5,000; ab131368; Abcam) for $2 \mathrm{~h}$ at room temperature. The signal was detected using an enhanced chemiluminescence detection kit (Amersham ECL RPN 2106 kit; GE Healthcare Life Sciences, Chalfont, UK). Grey density was analyzed using Quantity One analysis software v1.4.6 (Bio-Rad Laboratories, Inc. Hercules, CA, USA).

Immunochemical staining. Following treatment with indicated drugs, the cells were fixed in $4 \%$ paraformaldehyde at room temperature for $2 \mathrm{~h}$. Non-specific staining was blocked by $0.1 \mathrm{M}$ PBS containing 10\% goat serum (Hyclone; GE Healthcare Life Sciences) with $0.4 \%$ Triton X-100 (Sigma-Aldrich; Merck KgaA, Darmstadt, Germany) at room temperature for $2 \mathrm{~h}$. The cells mounted on coverslip were incubated with anti-PTEN antibody (1:400, no. 9552; Cell Signaling Technology, Inc.) in $0.1 \mathrm{M}$ PBS containing $5 \%$ goat serum and $0.4 \%$ Triton $\mathrm{X}-100$ overnight at $4^{\circ} \mathrm{C}$. Sections were washed three times (15 min each) in PBS and incubated with Alexa Fluor 594 goat anti-rabbit IgG (1:200, B40944; Thermo Fisher Scientific, Inc.) for $2 \mathrm{~h}$ at room temperature. Fluoroshield mounting media 

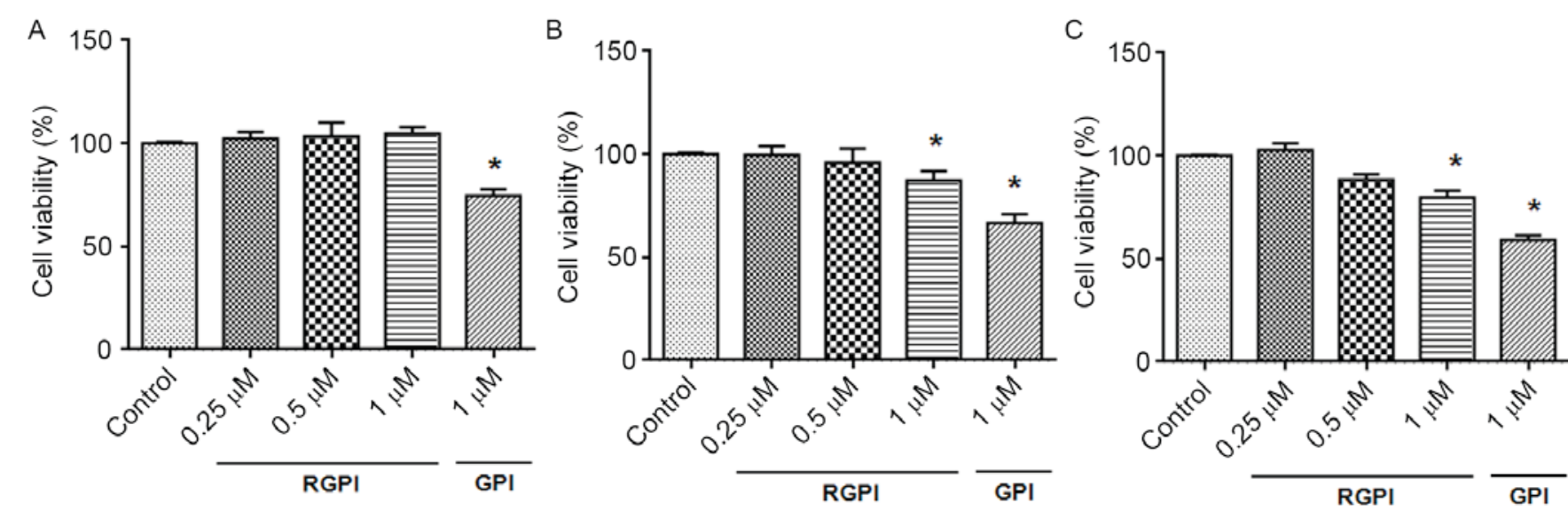

Figure 1. Effects of reduced $\beta 2 \mathrm{GPI}$ on cell viability in human umbilical cord veins. (A) The cells were incubated with non-reduced or reduced $\beta 2 \mathrm{GPI}$ at differing concentrations for (A) 24, (B) 48 and (C) $72 \mathrm{~h}$. Data were presented as the mean \pm standard error of the mean A total of 6 repeats were carried out in each group. ${ }^{*} \mathrm{P}<0.05$ vs. control. $\beta 2 \mathrm{GPI}, \beta 2$ glycoprotein I; RGPI, reduced GPI.

(ab104140; Abcam) was used to preserve the fluorescence of the stained samples. The images were obtained using Olympus Fluorescence Microscopy (Olympus Corporation, Japan).

Statistical analysis. The data are presented as the mean \pm standard error of mean. Statistical analyses of the data were performed using Student's t-test or one-way analysis of variance followed by Newman-Keuls multiple comparisons post-hoc test, using version 17.0 of SPSS (SPSS, Inc., Chicago, IL, USA). $\mathrm{P}<0.05$ was considered to indicate a statistically significant difference.

\section{Results}

Reduced $\beta 2$ GPI decreases high glucose-induced cell death in HUVECS. Initially, the present study detected the cell viability following reduced $\beta 2 \mathrm{GPI}$ treatment. As presented in Fig. 1, the results demonstrated that reduced $\beta 2 \mathrm{GPI}$ at the concentration range of 0.25 to $1 \mu \mathrm{M}$ did not affect cell viability following $24 \mathrm{~h}$ treatment. Conversely, $1 \mu \mathrm{M} \beta 2 \mathrm{GPI}$ treatment for $24 \mathrm{~h}$ significantly decreased the cell viability to a $70 \%$ level. A total of $48 \mathrm{~h}$ following treatment, $1 \mu \mathrm{M}$ reduced $\beta 2 \mathrm{GPI}$ slightly decreased the viability and $1 \mu \mathrm{M} \beta 2 \mathrm{GPI}$ significantly decreased the cell viability. A total of $72 \mathrm{~h}$ following treatment, reduced $\beta 2 \mathrm{GPI}$ at the concentration of $1 \mu \mathrm{M}$ significantly decreased the cell viability of HUVECs. A total of $0.5 \mu \mathrm{M}$ reduced $\beta 2 \mathrm{GPI}$ did not have cytotoxic action in HUVECs following 24-48 h treatment. However, $\beta 2 \mathrm{GPI}$ is toxic to HUVECs. In the following experiments, $0.5 \mu \mathrm{M}$ reduced $\beta 2 \mathrm{GPI}$ was selected to investigate the potential mechanisms.

HUVECs are sensitive to high glucose. As presented in Fig. 2, following $44.4 \mathrm{mM}$ glucose treatment for $48 \mathrm{~h}$, the cell viability decreased to $50 \%$, whereas reduced $\beta 2$ GPI significantly mitigated high glucose-induced cell loss (cell viability, $85 \%)$. Non-reduced $\beta 2$ GPI further decreased the cell viability compared with high glucose group. However, the vehicle (TRX-1, DTT and glutathione) did not have protective action. As the control, reduced $\beta 2$ GPI did not affect cell viability in HUVECs. These results suggested that $0.5 \mu \mathrm{M}$ reduced

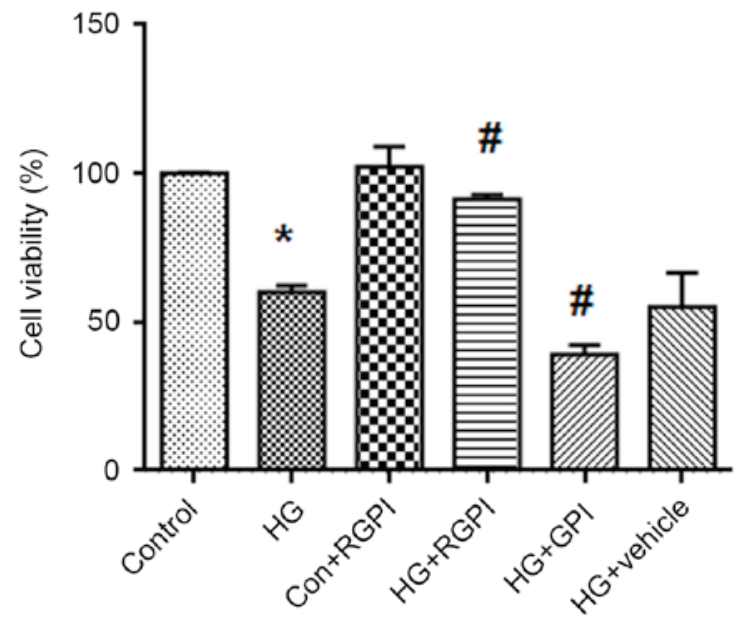

Figure 2. Effects of reduced $\beta 2 \mathrm{GPI}$ on high glucose induced cell death in human umbilical cord veins. The cells were incubated with reduced $\beta 2 \mathrm{GPI}$ or vehicle and high glucose for $48 \mathrm{~h}$. Data are presented as the mean \pm standard error of the mean. A total of six repeats were carried out in each group. ${ }^{*} \mathrm{P}<0.05$ vs. control. ${ }^{\#} \mathrm{P}<0.05$ vs. HG group. $\beta 2 \mathrm{GPI}, \beta 2$ glycoprotein I; HG, high glucose; RGPI, reduced GPI; Con, control.

$\beta 2$ GPI was beneficial for cell survival in high glucose treated HUVECs.

Reduced $\beta 2 G P I$ reverses high glucose-induced increase of PTEN. The present study detected PTEN expression following high glucose treatment for $48 \mathrm{~h}$. As presented in in Fig. 3A, high glucose treatment for $48 \mathrm{~h}$ significantly elevated PTEN levels. Reduced $\beta 2$ GPI significantly decreased PTEN expression in high glucose-treated cells, whereas reduced $\beta 2$ GPI did not influence PTEN level in untreated HUVECs. Immunochemical staining verified the results in Fig. 3B. In control, control + reduced $\beta 2 \mathrm{GPI}$ and high glucose + reduced $\beta 2$ GPI groups, PTEN was weakly expressed. PTEN is a negative regulator of AKT phosphorylation. The present study additionally detected p-AKT and AKT levels. It was demonstrated that high glucose decreased the p-AKT/AKT level, which was reversed by reduced $\beta 2$ GPI treatment (Fig. 3C). In addition, the PTEN inhibitor bpV was applied. As indicated, 
A

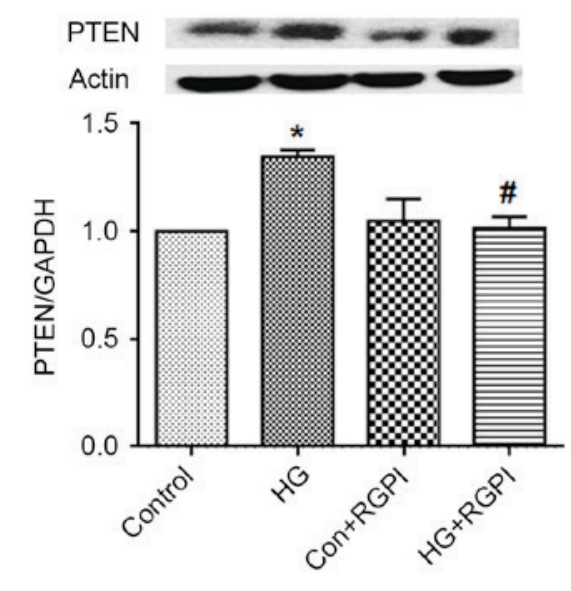

C

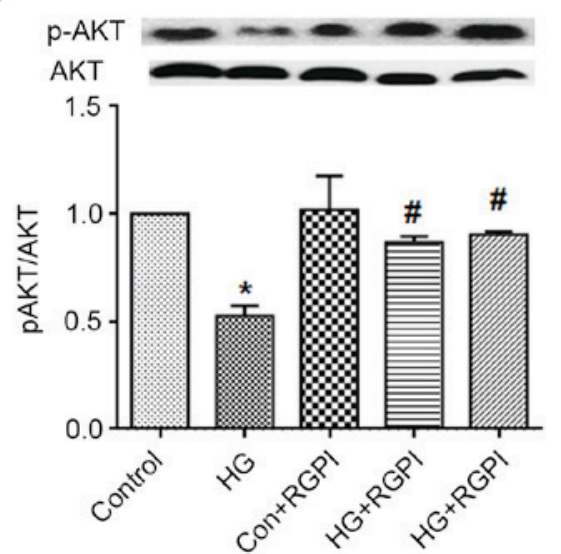

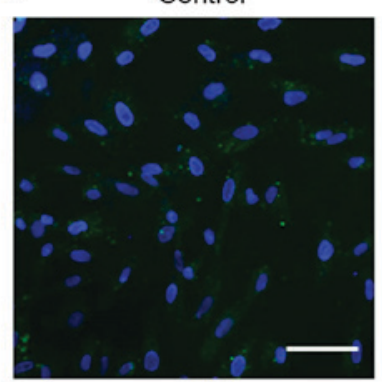

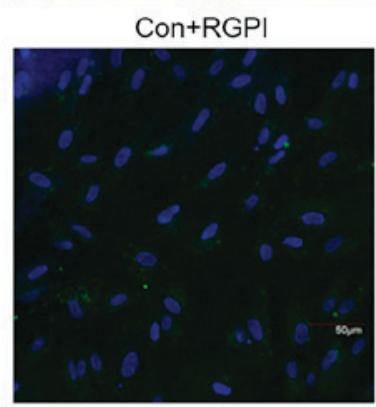

D

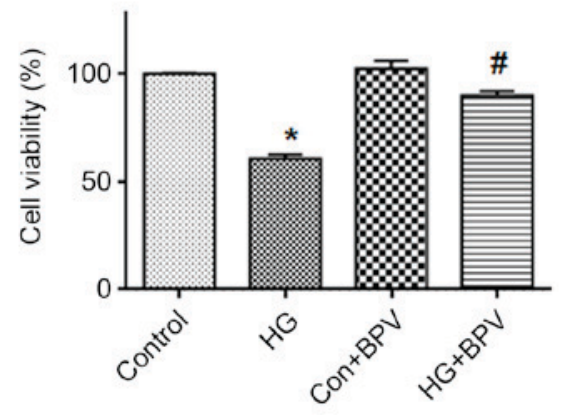

Figure 3. Effects of reduced $\beta 2 \mathrm{GPI}$ on high glucose-induced PTEN expression in human umbilical cord veins. Cells were incubated with reduced or non-reduced $\beta 2 \mathrm{GPI}$ for $48 \mathrm{~h}$ in absence or presence of high glucose. Representative images of PTEN expression levels detected via (A) immunoblotting and (B) immunohistochemical staining. Scale bar: $50 \mu \mathrm{m}$. (C) Detection of p-AKT expression via immunoblotting. (D) PTEN inhibitor reversed high glucose-induced cell death. Data are presented as the mean \pm standard error of the mean. A total of six repeats were carried out in each group. "P<0.05 vs. control. ${ }^{~} \mathrm{P}<0.05$ vs. HG group. $\beta 2 \mathrm{GPI}, \beta 2$ glycoprotein I; HG, high glucose; RGPI, reduced GPI; Con, control; PTEN, phosphatase and tensin homolog; BPV, PTEN inhibitor; AKT, protein kinase $\mathrm{B}$; p, phosphorylated.

$\mathrm{bpV}(1 \mu \mathrm{M})$ additionally upregulated the p-AKT/AKT level compared with the high glucose treated group. If reduced $\beta 2$ GPI prevents high glucose-induced cell loss via upregulation of PTEN, application of a PTEN inhibitor should exhibit a similar effect on high glucose-induced cell loss. As presented in Fig. 3D, $1 \mu \mathrm{M}$ bpV mitigated high glucose-induced cell loss, however did not affect cell viability in normal HUVECs.

\section{Reduced $\beta 2 G P I$ reverses high glucose-induced intracellular} free $\mathrm{Ca}^{2+}$ level. The intracellular free $\mathrm{Ca}^{2+}$ level was additionally detected. As presented in Fig. 4, high glucose incubation increased the intracellular calcium level, which was subsequently reversed by reduced $\beta 2 \mathrm{GPI}$ treatment. Conversely, reduced $\beta 2 \mathrm{GPI}$ did not influence the calcium influx in normal HUVECs compared with the control.

Reduced $\beta 2$ GPI reverses high glucose-induced decrease of $N O$ production and NOS activity. The present study detected NO production and NOS activity. As demonstrated in Fig. 5, high glucose significantly decreased NO production following $48 \mathrm{~h}$ treatment. The treatment with reduced $\beta 2 \mathrm{GPI}$ and $\mathrm{bpV}$

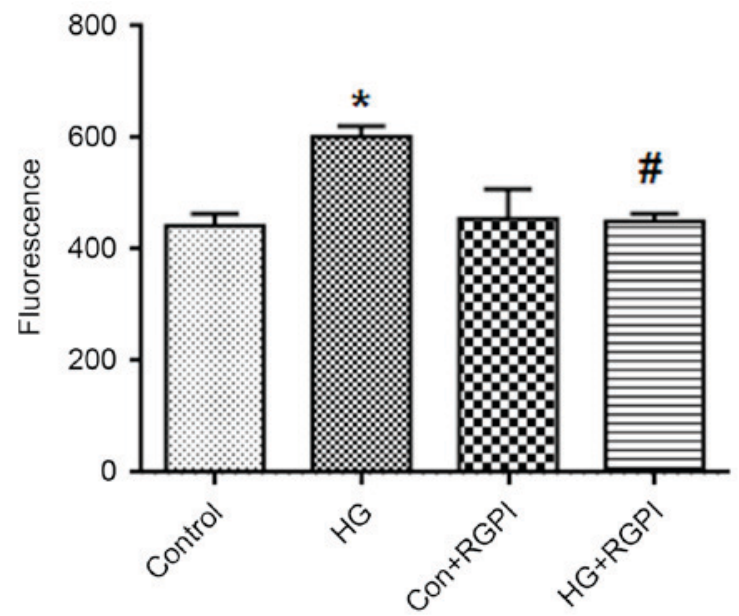

Figure 4. Effects of reduced $\beta 2$ GPI on intracellular free calcium levels in high glucose-induced human umbilical cord veins. The cells were incubated with reduced or non-reduced $\beta 2$ GPI for $48 \mathrm{~h}$ in the presence or absence of high glucose. Data are presented as the mean \pm standard error of the mean. A total of six repeats were carried out in each group. ${ }^{*} \mathrm{P}<0.05$ vs. control. ${ }^{\#} \mathrm{P}<0.05$ vs. HG group. $\beta 2 \mathrm{GPI}, \beta 2$ glycoprotein I; HG, high glucose; RGPI, reduced GPI; Con, control. 


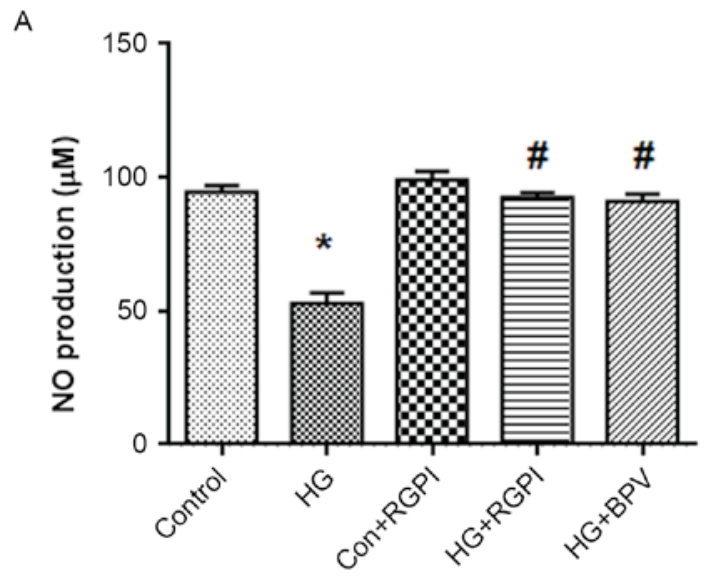

B

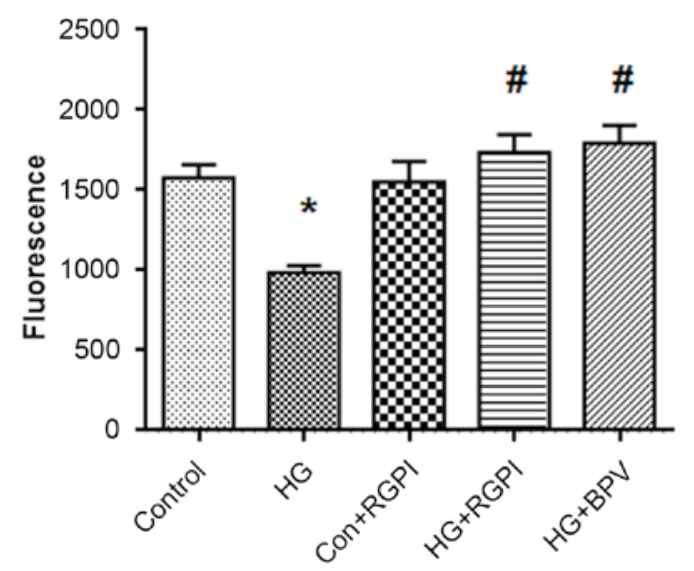

Figure 5. Effects of reduced $\beta 2 \mathrm{GPI}$ on NO production in high glucose-induced human umbilical cord veins. The cells were incubated with reduced $\beta 2 \mathrm{GPI}$ or BVP with high glucose for $48 \mathrm{~h}$ and (A) NO production and (B) NOS activity were detected. Data are presented as the mean \pm standard error of the mean. A total of six repeats were carried out in each group. ${ }^{*} \mathrm{P}<0.05$ vs. control.

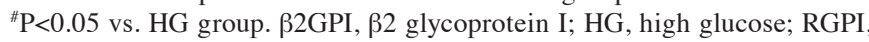
reduced GPI; Con, control; NO, nitric oxide; NOS, nitric oxide synthase; BVP, phosphatase and tensin homolog inhibitor.

eliminated the effects of high glucose on NO production. NOS is a primary enzyme responsible for NO synthesis, therefore its activity was detected. It was demonstrated that high glucose treatment decreased NOS activity. Reduced $\beta 2 \mathrm{GPI}$ and bpV significantly increased the NOS activities.

Reduced $\beta 2$ GPI reverses high glucose-induced increase of COX-2 activity. The present study detected COX-2 activity following reduced $\beta 2 \mathrm{GPI}$ treatment. As presented in Fig. 6, high glucose treatment for $48 \mathrm{~h}$ significantly elevated COX-2 activity. Reduced $\beta 2 \mathrm{GPI}$, in addition to $\mathrm{bpV}$, significantly decreased the COX-2 activity.

\section{Discussion}

The present study demonstrated the novel effect of RGPI on high glucose-induced injury in HUVECs. Reduced $\beta 2$ GPI reversed high glucose-induced cell injury, however, these effects were not observed with non-reduced GPI. High glucose resulted in accumulation of PTEN in HUVECs, which inhibited AKT phosphorylation, whereas RGPI reversed that signaling pathway.

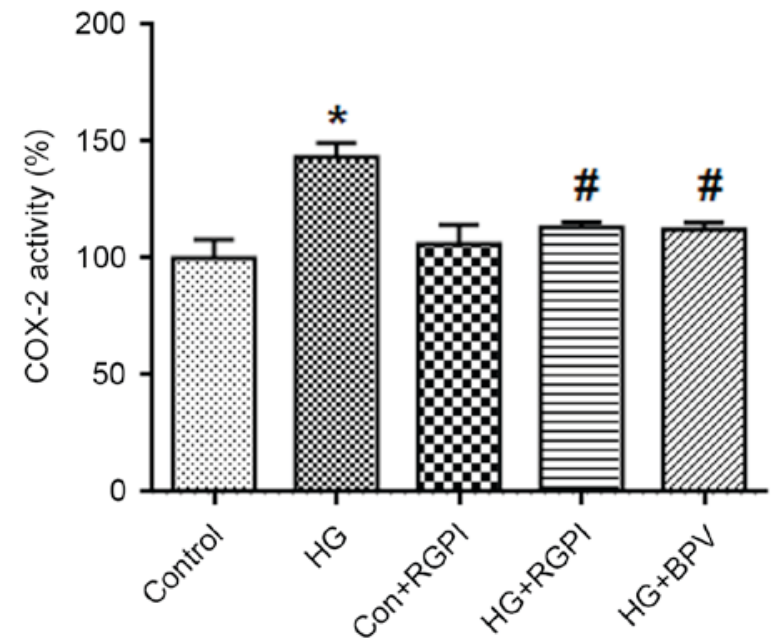

Figure 6. Effects of reduced $\beta 2 \mathrm{GPI}$ on COX-2 activity in high glucose-induced human umbilical cord veins. The cells were incubated with reduced $\beta 2 \mathrm{GPI}$ or BVP with high glucose for $48 \mathrm{~h}$. Data are presented as the mean \pm standard error of the mean. A total of six repeats were carried out in each group. ${ }^{*} \mathrm{P}<0.05$ vs. control. ${ }^{~} \mathrm{P}<0.05$ vs. HG group. $\beta 2 \mathrm{GPI}, \beta 2$ glycoprotein I; HG, high glucose; RGPI, reduced GPI; Con, control; NO, nitric oxide; NOS, nitric oxide synthase; BVP, phosphatase and tensin homolog inhibitor; COX-2, cyclooxygenase-2.

It has previously been reported that the proportion of reduced $\beta 2 \mathrm{GPI}$ is decreased in antiphospholipid syndrome $(18,19)$. This suggests that reduced $\beta 2$ GPI may exhibit a protective role in the development of the disease. Reduced $\beta 2 \mathrm{GPI}$, however not non-reduced $\beta 2 \mathrm{GPI}$, has been revealed to protect EAhy926 from oxidative stress induced endothelial cell damage (20). The present study demonstrated that a low concentration of reduced $\beta 2 \mathrm{GPI}$ protected against high glucose-induced cell death. Furthermore, reduced $\beta 2$ GPI did not affect the cell viability at a concentration of $0.25-1 \mu \mathrm{M}$, following $24 \mathrm{~h}$ incubation. It was observed that $1 \mu \mathrm{M}$ reduced $\beta 2$ GPI was toxic to HUVECs following 48 or $72 \mathrm{~h}$ incubation. The toxicity may have resulted from the re-oxidation of $\beta 2 \mathrm{GPI}$, as the non-reduced $\beta 2 \mathrm{GPI}$ was additionally detrimental to HUVECs. In contrast to previous studies which revealed that $\beta 2 \mathrm{GPI}$ and reduced $\beta 2 \mathrm{GPI}$ improve kidney fibrosis (21), the present study demonstrated that only the reduced form of $\beta 2 \mathrm{GPI}$ exerted protective effects in high glucose-induced cell injury in HUVECs. Regarding the function of reduced $\beta 2 \mathrm{GPI}$, potential re-oxidation may restrict its application. Therefore, the maintenance of the reduced state of $\beta 2 \mathrm{GPI}$ is critical for its protective function.

The present study identified the mechanisms involved in the protection of reduced $\beta 2 \mathrm{GPI}$ in high glucose induced cell injury. Consistent with a previous study (15), it was demonstrated that high glucose elicited cell death of HUVECs. Apoptosis of HUVECs occurs following high glucose treatment $(22,23)$. Kinase signaling pathways are important in the regulation of apoptosis. The AKT signaling pathway is an important cell survival signaling pathway $(24,25)$. The present study demonstrated that following high glucose treatment, p-AKT levels were decreased, which was consistent with the results of a previous study (26). In the reduced $\beta 2 \mathrm{GPI}$ treated group, the p-AKT level was increased compared with the model group. These data suggested that reduced $\beta 2 \mathrm{GPI}$ 
activated the survival signaling pathway. PTEN is a negative regulator of AKT phosphorylation (27). The accumulation of PTEN attenuates AKT phosphorylation. In accordance with a previous study (28), it was observed that the PTEN level was increased following high glucose treatment. Notably, the PTEN level decreased following reduced $\beta 2$ GPI treatment. The increased PTEN is critical for high glucose-induced cell death of HUVECs, as a PTEN inhibitor reversed high glucose-induced cell injury.

Calcium overloading is an important factor in cell death (29). The present study detected intracellular free calcium levels. High glucose elicited calcium overloading in HUVECs, which was eliminated by reduced $\beta 2$ GPI. Calcium activates calpain to elicit cell death. m-calpain requires a high concentration of calcium to exert its function to specifically degrade PTEN $(30,31)$. Therefore, the accumulation of PTEN was contrary to the increased calcium level following high glucose treatment. As PTEN may additionally be degraded by the ubiquitin proteasome system (UPS) (32), the accumulation of PTEN may result from damage of the UPS system under high glucose conditions. However, these interactions require further investigation.

NO is an important neurotransmitter secreted by vascular endothelial cells and has numerous functions, including inhibiting monocyte-macrophage and platelet adhesion, decreasing the monolayer permeability of vascular endothelial cells and reducing vascular endothelial cell and smooth muscle cell proliferation (33). A total of $30 \% \mathrm{NO}$ in the blood is derived from endothelial nitric oxide synthase genes expressed by vascular endothelial cells (34). The present study detected NO level and NOS activity under high glucose conditions. Results demonstrated that high glucose decreased NO level and NOS activity and the abnormalities of $\mathrm{NO}$ genesis were prevented by reduced $\beta 2$ GPI application. Notably, impaired NO production and the NOS activity were reversed following PTEN inhibitor application.

Prostaglandins COX may additionally contribute to hyperglycemia-induced endothelial dysfunction. The present study demonstrated that high glucose treatment induced upregulation of COX-2, which was consistent with previous studies $(35,36)$. As suggested, increased function of COX-2 may result in the reduced NO availability and altered prostanoid profile in human endothelial cells (35). Additionally, PTEN is involved in the regulation of COX-2 activity and application of the PTEN inhibitor reversed the high glucose-induced upregulation of COX-2 activity.

In conclusion, the present study provides novel data suggesting the protective effects of reduced $\beta 2 \mathrm{GPI}$ in high glucose induced cell injury in HUVECs. High glucose-induced accumulation of PTEN may be important in the increase of cell death, decrease in NO production and COX-2 activation. Further studies are required in order to maintain the reduced state of $\beta 2 \mathrm{GPI}$, however the findings identify the therapeutic potential of reduced $\beta 2 \mathrm{GPI}$ in the treatment of vascular disorders in DM.

\section{Acknowledgements}

The authors gratefully acknowledge the support from the National Natural Science Foundation of China (grant no. 81300665$)$.

\section{References}

1. Ceriello A: Postprandial hyperglycemia and diabetes complications: Is it time to treat? Diabetes 54: 1-7, 2005.

2. Tsukada S, Masuda H, Jung SY, Yun J, Kang S, Kim DY, Park JH, Ji ST, Kwon SM and Asahara T: Impaired development and dysfunction of endothelial progenitor cells in type 2 diabetic mice. Diabetes Metab 43: 154-162, 2017.

3. Ren Y, Tao S, Zheng S, Zhao M, Zhu Y, Yang J and Wu Y: Salvianolic acid B improves vascular endothelial function in diabetic rats with blood glucose fluctuations via suppression of endothelial cell apoptosis. Eur J Pharmacol 791: 308-315, 2016.

4. Jia G, Durante W and Sowers JR: Endothelium-derived hyperpolarizing factors: A potential therapeutic target for vascular dysfunction in obesity and insulin resistance. Diabetes 65: 2118-2120, 2016.

5. Rahgozar S: Revisiting beta 2 glycoprotein I, the major autoantigen in the antiphospholipid syndrome. Iran J Immunol 9: 73-85, 2012.

6. Blank M and Shoenfeld Y: Beta-2-glycoprotein-I, infections, antiphospholipid syndrome and therapeutic considerations. Clin Immunol 112: 190-199, 2004

7. Rioche M and Masseyeff R: Synthesis of plasma beta 2 glycoprotein I by human hepatoma cells in tissue culture. Biomedicine 21: 420-423, 1974.

8. Schwarzenbacher R, Zeth K, Diederichs K, Gries A, Kostner GM, Laggner P and Prassl R: Crystal structure of human beta2-glycoprotein I: Implications for phospholipid binding and the antiphospholipid syndrome. EMBO J 18: 6228-6239, 1999.

9. de Groot PG and Meijers JC: $\beta(2)$-Glycoprotein I: Evolution, structure and function. J Thromb Haemost 9: 1275-1284, 2011.

10. Petri M: Update on anti-phospholipid antibodies in SLE: The Hopkins' lupus cohort. Lupus 19: 419-423, 2010.

11. A gar C, de Groot PG, Marquart JA and Meijers JC: Evolutionary conservation of the lipopolysaccharide binding site of $\beta_{2}$-glycoprotein I. Thromb Haemost 106: 1069-1075, 2011.

12. Jankowski M, Vreys I, Wittevrongel C, Boon D, Vermylen J, Hoylaerts MF and Arnout J: Thrombogenicity of beta 2-glycoprotein I-dependent antiphospholipid antibodies in a photochemically induced thrombosis model in the hamster. Blood 101: 157-162, 2003.

13. Ioannou Y, Zhang JY, Passam FH, Rahgozar S, Qi JC, Giannakopoulos B, Qi M, Yu P, Yu DM, Hogg PJ and Krilis SA: Naturally occurring free thiols within beta 2 -glycoprotein I in vivo: Nitrosylation, redox modification by endothelial cells, and regulation of oxidative stress-induced cell injury. Blood 116: 1961-1970, 2010

14. Yu P, Passam FH, Yu DM, Denyer G and Krilis SA: Beta2-glycoprotein I inhibits vascular endothelial growth factor and basic fibroblast growth factor induced angiogenesis through its amino terminal domain. J Thromb Haemost 6: 1215-1223, 2008.

15. Lv Q, Xue Y, Li G, Zou L, Zhang X, Ying M, Wang S, Guo L, Gao Y, Li G, et al: Beneficial effects of evodiamine on P2X(4)-mediated inflammatory injury of human umbilical vein endothelial cells due to high glucose. Int Immunopharmacol 28: 1044-1049, 2015.

16. Lin KY, Wang HH, Lai ST, Pan JP and Chiang AN: beta(2)-glycoprotein I protects J774A.1 macrophages and human coronary artery smooth muscle cells against apoptosis. J Cell Biochem 94: 485-496, 2005.

17. Zhang R, Zhou SJ, Li CJ, Wang XN, Tang YZ, Chen R, Lv L, Zhao Q, Xing QL, Yu DM and Yu P: C-reactive protein/oxidised low-density lipoprotein/beta2-glycoprotein I complex promotes atherosclerosis in diabetic BALB/c mice via p38mitogenactivated protein kinase signal pathway. Lipids Health Dis 12: 42, 2013.

18. Blank M, Baraam L, Eisenstein M, Fridkin M, Dardik R, Heldman Y, Katchalski-Katzir E and Shoenfeld Y: $\beta 2$-Glycoprotein-I based peptide regulate endothelial-cells tissue-factor expression via negative regulation of pGSK $3 \beta$ expression and reduces experimental-antiphospholipid-syndrome. J Autoimmun 37: 8-17, 2011.

19. Rand JH, Wu XX, Quinn AS, Chen PP, Hathcock JJ and Taatjes DJ: Hydroxychloroquine directly reduces the binding of antiphospholipid antibody-beta2-glycoprotein I complexes to phospholipid bilayers. Blood 112: 1687-1695, 2008. 
20. Passam FH, Rahgozar S, Qi M, Raftery MJ, Wong JW, Tanaka K, Ioannou Y, Zhang JY, Gemmell R, Qi JC, et al: Redox control of $\beta 2$-glycoprotein I-von Willebrand factor interaction by thioredoxin-1. J Thromb Haemost 8: 1754-1762, 2010.

21. Wang T, Chen SS, Chen R, Yu DM and Yu P: Reduced beta 2 glycoprotein I improves diabetic nephropathy via inhibiting TGF- 31 -p38 MAPK pathway. Int J Clin Exp Pathol 8: 2321-2333, 2015.

22. Liu X, Chen D, Wu Z, Li J, Li J,Zhao H and Liu T: Ghrelin inhibits high glucose-induced $16 \mathrm{HBE}$ cells apoptosis by regulating Wnt/ $\beta$-catenin pathway. Biochem Biophys Res Commun 477: 902-907, 2016

23. Liu Y, Tian X, Li Y, Liu D, Liu M, Zhang X, Zhang Q, Yan C and Han Y: Up-regulation of CREG expression by the transcription factor GATA1 inhibits high glucose- and high palmitate-induced apoptosis in human umbilical vein endothelial cells. PloS One 11: e0154861, 2016.

24. Zhu G, Wang X, Wu S and Li Q: Involvement of activation of PI3K/Akt pathway in the protective effects of puerarin against MPP+-induced human neuroblastoma SH-SY5Y cell death Neurochem Int 60: 400-408, 2012.

25. Zhu G, Wang Y, Li J and Wang J: Chronic treatment with ginsenoside $\mathrm{Rg} 1$ promotes memory and hippocampal long-term potentiation in middle-aged mice. Neuroscience 292: 81-89, 2015.

26. Ho FM, Lin WW, Chen BC, Chao CM, Yang CR, Lin LY, Lai CC, Liu SH and Liau CS: High glucose-induced apoptosis in human vascular endothelial cells is mediated through NF-kappaB and c-Jun NH2-terminal kinase pathway and prevented by PI3K/Akt/eNOS pathway. Cell Signal 18: 391-399, 2006.

27. Tachibana N, Cantrup R, Dixit R, Touahri Y, Kaushik G, Zinyk D, Daftarian N, Biernaskie J, McFarlane S and Schuurmans C: Pten regulates retinal amacrine cell number by modulating Akt, Tgf $\beta$ and Erk signaling. J Neurosci 36: 9454-9471, 2016.
28. Hou Q, Lei M, Hu K and Wang M: The effects of high glucose levels on reactive oxygen species-induced apoptosis and involved signaling in human vascular endothelial cells. Cardiovasc Toxicol 15: 140-146, 2015

29. Choi SE, Min SH, Shin HC, Kim HE, Jung MW and Kang Y: Involvement of calcium-mediated apoptotic signals in H2O2-induced MIN6N8a cell death. Eur J Pharmacol 547: 1-9, 2006.

30. Briz V,Hsu YT,LiY,LeeE,BiXandBaudryM:Calpain-2-mediated PTEN degradation contributes to BDNF-induced stimulation of dendritic protein synthesis. J Neurosci 33: 4317-4328, 2013.

31. Zhu G, Liu Y, Wang Y, Bi X and Baudry M: Different patterns of electrical activity lead to long-term potentiation by activating different intracellular pathways. J Neurosci 35: 621-633, 2015.

32. Chen X, Du YM, Xu F, Liu D and Wang YL: Propofol prevents hippocampal neuronal loss and memory impairment in cerebral ischemia injury through promoting PTEN degradation. J Mol Neurosci 60: 63-70, 2016.

33. Botham KM and Wheeler-Jones CP: Postprandial lipoproteins and the molecular regulation of vascular homeostasis. Prog Lipid Res 52: 446-464, 2013.

34. McCullagh KJ, Cooney R and O'Brien T: Endothelial nitric oxide synthase induces heat shock protein HSPA6 (HSP70B') in human arterial smooth muscle cells. Nitric Oxide 52: 41-48, 2016.

35. Sheu ML, Ho FM, Yang RS, Chao KF, Lin WW, Lin-Shiau SY and Liu SH: High glucose induces human endothelial cell apoptosis through a phosphoinositide 3-kinase-regulated cyclooxygenase-2 pathway. Arterioscler Thromb Vasc Biol 25: 539-545, 2005.

36. Chen JH,Hsiao G,Lee AR, Wu CC and Yen MH: Andrographolide suppresses endothelial cell apoptosis via activation of phosphatidyl inositol-3-kinase/Akt pathway. Biochem Pharmacol 67: 1337-1345, 2004. 